\title{
Generator overload reduction using smart power management
}

\author{
Cosimo Spagnolo, Sharmila Sumsurooah, Christoper Ian Hill, Member, IEEE, Serhiy Bozhko, Member, IEEE \\ University of Nottingham \\ Power Electronics and Machine Control, PEMC \\ Nottingham, United Kingdom \\ ezzcs2@nottingham.ac.uk
}

\begin{abstract}
Weight reduction is a key driver in the aerospace sector. Every kilogram of weight reduction has significant benefits over the aircraft's life cycle. This paper introduces a smart power management technique which is able to reduce the overload on the main aircraft generators. If implemented this would allow the generator size to be reduced at the design stage as no overload capability would be required. The paper first introduces the theoretical and mathematical background of the smart power management controller, utilizing both Linear Temporal Logic and a Finite State Machine. A case study is then used to show the derivation of the controller and demonstrate how smart reconfiguration of power paths (e.g. peak request of power) can reduce the overload on the main aircraft generators.
\end{abstract}

Keywords-MEA, AEA, Aircraft Electric Power System, HV270DC, Smart Network

\section{INTRODUCTION}

The electrical power systems (EPSs) of aircrafts have been rapidly increasing in capacity and complexity in the recent years, with an electrical demand of more than $1 \mathrm{MW}$ on the Boeing 787 Dreamliner [1]. This trend in aircraft electrification is predicted to become more significant in the near future, with much research being conducted on the more electric aircraft MEA. A key aspect of the MEA concept is the replacement of the traditional pneumatic and hydraulic loads by electrical equivalents. These new electrical systems have many benefits in that they are more reliable, easier to replace and maintain, highly efficient contributing to the reduction of greenhouse emissions [2-4]. Important advancements are being made in the development of EPSs for the All Electric Aircraft (AEA) [5, 6]. Recent studies have demonstrated the advantages of using the high voltage DC systems (HV270DC) for AEA [7]. The challenges that are to be resolved are the weight, volume, cost and reliability of the electrical power networks. This paper proposes a potential solution for reducing the weight of such EPS. The increasing use of power electronic devices, contactors and energy storage devices in aircraft EPS make such power systems more flexible and easily reconfigurable. The flexibility of the power electronic based systems can be exploited for various purposes such as introducing more safety features in the network or saving energy on-board. Achieving such objectives may lie in the development of smart controllers. These controllers can be designed to alter the configurations of the power network such that defined energy management strategies are implemented and safety rules are respected. The choice of the control strategy has a significant impact on the objective that is to be achieved. The type of tools used to program the controller is also important. A number of programming languages have been used for the design of the controller, as reported in recent studies. First, the use of the "C language" was applied for the design of the controller. But, with the evolution of electrical networks, which are becoming more complex, more sophisticated languages and set of logics have to be used. "Fuzzy logic"[8, 9] and CLIPS language (C language integrated production system)[10] are used to program faster and more efficient controllers for EPSs, where all the decisions are taken based on mathematical and heuristic approach together. Recent studies have considered the use of the Linear Temporal Logic (LTL). LTL, introduced by Pnueli [11], is an extension of propositional logic and incorporates notions of temporal ordering[12]. A suitable tools that can be considered to manage the EPS, in terms of reactive system, is the Finite State Machine (FSM) . The FSM is a computational model, where the behaviour of the system can be modelled as a set of states and transitions [13], and has several advantages [14]:

\section{- FSM is easy to use (based on graphical language) \\ - FSM has powerful algorithms}

In this work, a control strategy is designed to control the power flow of a representative MEA EPS with the aim to reducing overload on its generators while ensuring safety of the electrical network. This would allow the generator size to be reduced at the design stage [15]. This work demonstrates how FSM is used to design the controller and implement the control strategy. The paper is divided in four sections. Section II gives the theoretical background of the electrical power system of the MEA and introduces the FSM tool. In section III, a case study is presented where the control strategy is applied to the EPS under study in Simulink, and the results are discussed. Section IV presents the conclusion.

\section{THEORETICAL BACKGROUND}

This section first gives an overview of a representative EPS of the MEA. It then introduces the control logic that is applied to control such an EPS under study, with the aim to reducing generator overload. 
The conventional EPSs for modern aircrafts are supplied by $115 \mathrm{~V}$ line to neutral AC voltage with a line frequency of 400 $\mathrm{Hz}$. With this configuration the electrical generators are connected to the main engines (in most cases each engine supplies two generators) via mechanical drive, which is used to keep the mechanical speed and the electrical frequency constant on the electric bus[2]. These are therefore the primary electrical power sources. The generators supply power to a number of loads, such as an induction motor driving a hydraulic pump or lighting, through a set of buses. There are multiple buses in the aircraft to accommodate redundancy for emergency operations purposes. The buses are interconnected through contactors (switching devices), which can be either opened or closed, based on the required configuration of the system. The transformer rectifier unit (TRU) is used to supply the electronic devices, which can be radars or cockpit controls. Moreover, emergency batteries are also placed on-board to provide supplementary power if needed. Further, there is a fast increase in the use of power electronic converters in MEA EPS.

The flexibility of power electronic based systems of the MEA can be exploited to perform energy management functions or to enforce safety measures through the application of a smart controller. The controller has the task to reconfigure the system states so that the energy management and/or safety rules are respected, by acting on contactors and power electronic converters (PEC). This approach is based on the reconfiguration strategy [16]. The languages for setting the reconfiguration strategy can use Knowledge-based system[16], which consist of the implementation of business and mandatory rules in a single framework. The basic structure of a rule is made of two main parts, which consist of a condition part (IF) and action part (THEN). Whenever all the rule's conditions are fulfilled, the rule is satisfied. The main strength of the knowledge based system is its capacity to activate the rules whenever the conditions are fulfilled. Whereas this capacity is not provided in traditional procedural programming where conditions of an "if" test are evaluated at a particular point of the program. The priority level of each execution can be specified to each rule, so if several rules can be fired at the same time, the highest priority rule will be fired first $[16,17]$. Since the controller must be able to operate on the EPS applying a set of specific rules, these rules need to be expressed ("synthetized") in a mathematical language and translated for the processor, looking at the EPS as a reactive system. A first approach about synthesis of reactive systems can be found in $[12,18]$. The Linear Temporal Logic (LTL)[11] can be considered as a good tool for managing the power flow of an EPS. LTL is an extension of propositional logic that incorporates notions of temporal ordering to reason about correctness over a sequence of states. In reactive systems (i.e., systems which react to a dynamic, a priori unknown environment)[19], correctness will depend not only on inputs and outputs of a computation, but on execution of the system as well. Temporal logic is a formalism well-suited for these types of problems in which the system must react to a variable environment. An EPS can be considered a reactive system[13]. The finite state machine (FSM) which combines "Knowledgebased method" and LTL notions, has been chosen as a suitable tool for the design of the controller. FSM is a computation model that can be implemented with hardware or software and be used to simulate sequential logic. FSM can be used to model problems in many fields including mathematics and artificial intelligence. In a FSM the behaviour of the system can be modelled as a set of states and transitions between states. FSM can be expressed as (1)

$$
f\left(\sum, S, s_{0}, \delta, F\right)
$$

In equation (1), $\sum$ represents a finite set of symbols, $S$ is a finite set of sates, $s_{0}$ is the initial state, so that $s_{0} \in S, \delta$ is a state transition function as defined in (2) and $F$ is finite set of final states.

$$
\delta: S \times \sum \rightarrow S
$$

An example of the formulation of a FSM is depicted in Fig. 1.

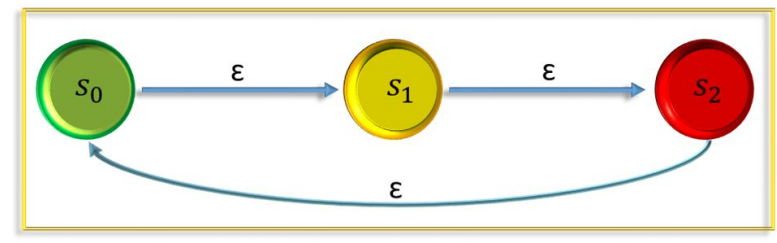

Fig. 1: Example of reactive system

The following equations describe the system in Fig. 1

$$
\begin{aligned}
\sum & =[\varepsilon] \\
S & =\left[s_{0}, s_{1}, s_{2}\right] \\
\delta=\left[s_{0} / \varepsilon\right. & \left.\rightarrow s_{1}, s_{1} / \varepsilon \rightarrow s_{2}, s_{2} / \varepsilon \rightarrow s_{0}\right] \\
F & =s_{2}
\end{aligned}
$$

In order to design a smart controller based on the aforementioned tools, this paper adopts the following steps. (i) First the aircraft power system is modelled. (ii) Then the control strategy is defined (iii) the control rules are written as state transition tables (iv) and finally the set of logics are implemented in a suitable simulation environment. The next section describes a case study involving the design of a smart controller, based on the above-mentioned four steps.

\section{MEA - CASE OF STUDY}

\section{A. The system under study}

This section describes the representative power system, as depicted in Fig. 2, to which the control strategy is to be applied in this case study. 


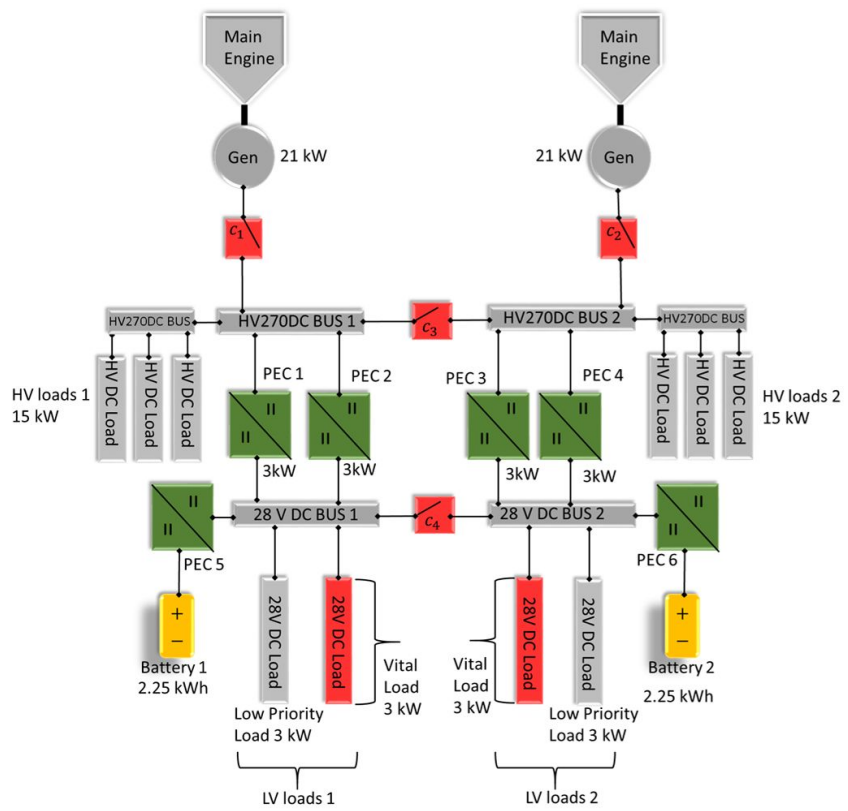

Fig. 2. Representative MEA EPS for the case study

The example MEA EPS, as shown in Fig. 2, is composed of two main generators of $21 \mathrm{~kW}$, each connected to the HV270DC main buses 1 and 2 through the contactors $C_{1}$ and $C_{2}$ respectively. The contactor $C_{3}$ is kept open during normal conditions of operation to avoid parallel connections of the two generators. In the event one of the generators should fail, contactor $C_{3}$ is closed to enable the healthy generator to supply both 'sides' of the network as shown in Fig. 2. The generators supply power to two sets of high voltage loads (HV loads 1 and 2) of $15 \mathrm{~kW}$ each and low voltage (LV) loads through four power electronics converter (PEC1, 2, 3 and 4) through LV buses 1 and 2 as shown in Fig. 2. The HV loads comprise deicing system, as will be explained later in this section. The four PECs, each of rating $3 \mathrm{~kW}$, are modelled as bidirectional converters, which help improve the reliability of the system by enabling power flow in both directions. The four PECs are connected in couple to LV buses 1 and 2; this design introduces redundancy in the power system and enables power to be supplied to the LV loads to some extent in case of one of the PEC fails. The LV loads consist of two low priority loads of 3 $\mathrm{kW}$ that can be shed if required and two vital loads of $3 \mathrm{~kW}$ each to which power has to be supplied uninterrupted. Moreover, the two batteries of $2.25 \mathrm{kWh}$ each are designed to provide supplementary power to the power system, and to the vital loads in particular, in case of faults in the electrical network. The PECs 5 and 6, as shown in Fig.2, are used to maintain the voltage of the LV buses at $28 \mathrm{~V}$. Since the focus of the paper is to show the performance of the control logic, all the components of the system model are developed as ideal devices in the Simulink environment.

\section{B. The Control strategy}

This section IIIB outlines the control strategy. This can be an energy management strategy or an approach to ensure safety of the EPS. The control strategy in this case study aims to reduce the overload on the generators of the EPS in Fig. 2, as will be explained later in this section. Further, it has to ensure certain safety measures such as supplying uninterrupted power to the vital loads, avoiding parallel connections of electrical sources or not discharging the batteries below a pre-set limit.

The HV loads, as shown in Fig. 2, consist of a de-icing system. The de-icing system is used in the aircraft to remove ice formations on the critical parts such as air foils leading edges, and require around $20-30 \%$ of the total power of the EPS[20]. Depending on the design of the generators, they can be permitted to go in overload for short period of times. However, such a design means an increase in weight [2]. In this work, the control strategy is devised such that the generators do not need to go in overload. During normal operations, i.e. no de-icing, the HV loads 1 and 2 consume $15 \mathrm{~kW}$ of power each, as shown in Table I under operation mode 1. The total power of the EPS is $42 \mathrm{~kW}$ in operation mode 1. During de-icing conditions, the $\mathrm{HV}$ loads 1 and 2 require an additional $6 \mathrm{~kW}$ of power each for the de-icing system to function, as described in Table I under operation mode 2. The total power required by the EPS is increased to $54 \mathrm{~kW}$.

A control strategy is to be devised to supply the surplus power to the de-icing system without overloading the generators which are rated at $21 \mathrm{~kW}$ each. This can be achieved by first shedding half of the low priority loads as shown in Table I under operation mode 2 . This action will lower the total power requirement of the power system in operation mode 2 from 54 $\mathrm{kW}$ to $51 \mathrm{~kW}$.

\begin{tabular}{|c|c|c|}
\hline & $\begin{array}{l}\text { Operation } \\
\text { mode } 1\end{array}$ & $\begin{array}{l}\text { Operation } \\
\text { mode } 2\end{array}$ \\
\hline$H V_{\text {bus } 1}$ & $15 \mathrm{~kW}$ & $21 \mathrm{KW}$ \\
\hline$H V_{\text {bus } 2}$ & $15 \mathrm{~kW}$ & $21 \mathrm{~kW}$ \\
\hline$L V_{\text {bus } 1}$ Vital load & $3 \mathrm{~kW}$ & $3 \mathrm{~kW}$ \\
\hline$L V_{\text {bus } 1}$ Low priority load & $3 \mathrm{~kW}$ & $1.5 \mathrm{~kW}$ \\
\hline$L V_{\text {bus } 2}$ Vital load & $3 \mathrm{~kW}$ & $3 \mathrm{~kW}$ \\
\hline$L V_{\text {bus } 2}$ Low priority load & $3 \mathrm{~kW}$ & $1.5 \mathrm{~kW}$ \\
\hline Total power & $42 \mathrm{~kW}$ & $51 \mathrm{~kW}$ \\
\hline
\end{tabular}

Secondly, the additional $9 \mathrm{~kW}$ required for the operation mode 2 should be supplied by the batteries. The batteries supply $6 \mathrm{~kW}$ to the de-icing system through two PECs operating in boost mode (PEC 1 and 4 selected in this study) and half of the non-essential loads which are not shed (2 times $1.5 \mathrm{~kW})$. It is to be ensured that the LV vital loads have uninterrupted power. In this case study, it is assumed that the state of charge (SOC) of the batteries are kept at $90 \%$ in normal operating conditions. In addition, the minimum SOC of the batteries should be $50 \%$; this reserve energy is to supply the vital loads in case of emergency. Hence, $40 \%$ of the total energy ( $\left.\mathrm{E}_{\text {tot }}\right)$ of the two batteries can be used to supply power to the de-icing system ( $\mathrm{P}_{\text {de-icing }}$ ) of $9 \mathrm{~kW}$ for a total duration $(\mathrm{t})$ of 12 minutes as shown in equation (7) below (i.e. 6 mins for the de-icing system on HV load 1 and HV 
load 2 respectively). Of note is that in the worst case scenario, the de-icing system is required to operate for 5 minutes [21]

$$
t=\frac{E_{\text {tot }} *(0.9-0.5)}{P_{\text {de-icing }}}=\frac{4.5 \mathrm{kWh} * 0.4}{9 \mathrm{KW}} \times 60=12 \text { minutes }
$$

\section{Strategy to logic}

Once the control strategy has been defined, it must be translated into a form that the controller can read and act upon. This work is based on the Finite state machine (FSM) and the control rules are written in state transition tables. The control strategy, which has been defined in the earlier subsection for this case study, describes the required behavior of the system under different operating conditions 1 and 2. The control strategy is first converted into a state transition table which the controller can read and then take required actions. The state table for this case study is shown in Table II. In the power system, the variables are the state of charge of batteries 1 and 2 referred to as SOC 1 and SOC 2 respectively. When the power system has a power demand for the de-icing system, depending on the values of SOC 1 and SOC2, the system will transition to states 1, 2, 3 or 4 as shown in Table II, and as described below.

TABLE II

\begin{tabular}{|c|c|c|}
\hline SOC & Battery 1: $50 \%<S O C<90 \%$ & Battery 1: SOC=50\% \\
\hline $\begin{array}{l}\text { Battery 2: } \\
50 \%<50 C<90 \%\end{array}$ & $\begin{array}{l}\text { State 1: } \\
\text { C4 closed } \\
\text { Batteries } 1,2 \text { connected } \\
\text { Load shedding on low priority load } \\
\text { DC/DC PEC } 1 \text { and PEC } 4 \text { operated in boost model and batteries } \\
1 / 2 \text { supply surge power } \\
\text { If SOC Battery } 1=50 \% \text {, go to state } 2 \\
\text { If SOC Battery } 2=50 \% \text {, go to state } 3 \\
\text { After power surge, go to State } 4\end{array}$ & $\begin{array}{l}\text { State 2: } \\
\text { C4 open } \\
\text { Load shedding on low priority load } \\
\text { Battery } 1 \text { disconnected; Battery } 2 \text { connected } \\
\text { DC/DC PEC 1and PEC } 4 \text { operated in boost model and battery } 2 \\
\text { supplies surge power } \\
\text { If SOC battery } 2=50 \% \text {, go to state } 3 \\
\text { After power surge, go to State } 4\end{array}$ \\
\hline $\begin{array}{l}\text { Battery 2: } \\
\text { SOC }=50 \%\end{array}$ & $\begin{array}{l}\text { State 3: } \\
\text { C4 closed } \\
\text { Battery } 2 \text { disconnected; Battery } 1 \text { connected } \\
\text { Load shedding on low priority load } \\
\text { DC/DC PEC } 1 \text { and PEC } 4 \text { operated in boost model and batteries } 1 \\
\text { supply surge power } \\
\text { If SOC Battery } 1=50 \% \text {, go to state } 2 \\
\text { After power surge, go to State } 4\end{array}$ & $\begin{array}{l}\text { State 4: } \\
\text { If the Generator is not in overload } \\
\text { - Charge batteries until } 90 \% \text { SOC (battery with lowest SOC charged } \\
\text { first) } \\
\text { - If } \mathrm{SOC} 1 \text { exceeds } 90 \% \text {, disconnect battery } 1 \text {, go to state } 4 \\
\text { - If SOC } 2 \text { exceeds } 90 \% \text {, disconnect battery } 2 \text {, go to state } 4 \\
\text { If the Generator is in overload } \\
\text { - No action to reduce generator overload }\end{array}$ \\
\hline
\end{tabular}

State 1: If SOC 1 and SOC 2 are between $50 \%$ and $90 \%$, (normally $90 \%$ at the start), both batteries supply power to the de-icing system with the PECs 1 and 4 in boost mode, and half of the non-essential loads that are not shed ( 2 times $1.5 \mathrm{~kW}$ ). The system is maintained in this state until SOC1 and/or SOC2 falls down to $50 \%$.

State 2: If SOC 1 reaches $50 \%$, battery 1 is disconnected to preserve energy for the vital load in case of emergency. Only battery 2 is used to supply the de-icing system and half of the low priority loads that are not shed.

State 3: State 3 is similar to state 2 . However, battery 1 instead of battery 2 supplies the additional requested power.

State 4: When SOC1 and SOC 2 both reach $50 \%$, the system is in state 4. Assuming that the SOC of the batteries are always at $90 \%$ during normal operation i.e. operating mode 1 , and that the worst case scenario of de-icing conditions i.e. operation mode 2 require energy from the batteries for a maximum duration of 5 minutes on HV loads 1 and 2 respectively, then state 4 is used to charge the batteries back to $90 \%$.

\section{Logic implementation}

The final step of the controller design is the implementation of the control logics in an appropriate simulation tool. For this case study, the control logics described in Table II, are applied to the representative MEA EPS in Fig. 2. The simulations have been performed in the Simulink environment and uses of State-flow function, which combine FSM and LTL operations [22]. Fig. 3 shows the source code for the states including the transitions between the states. In Fig. 2, the states are defined inside the blocks while the arrows define the transitions from one state to another. 


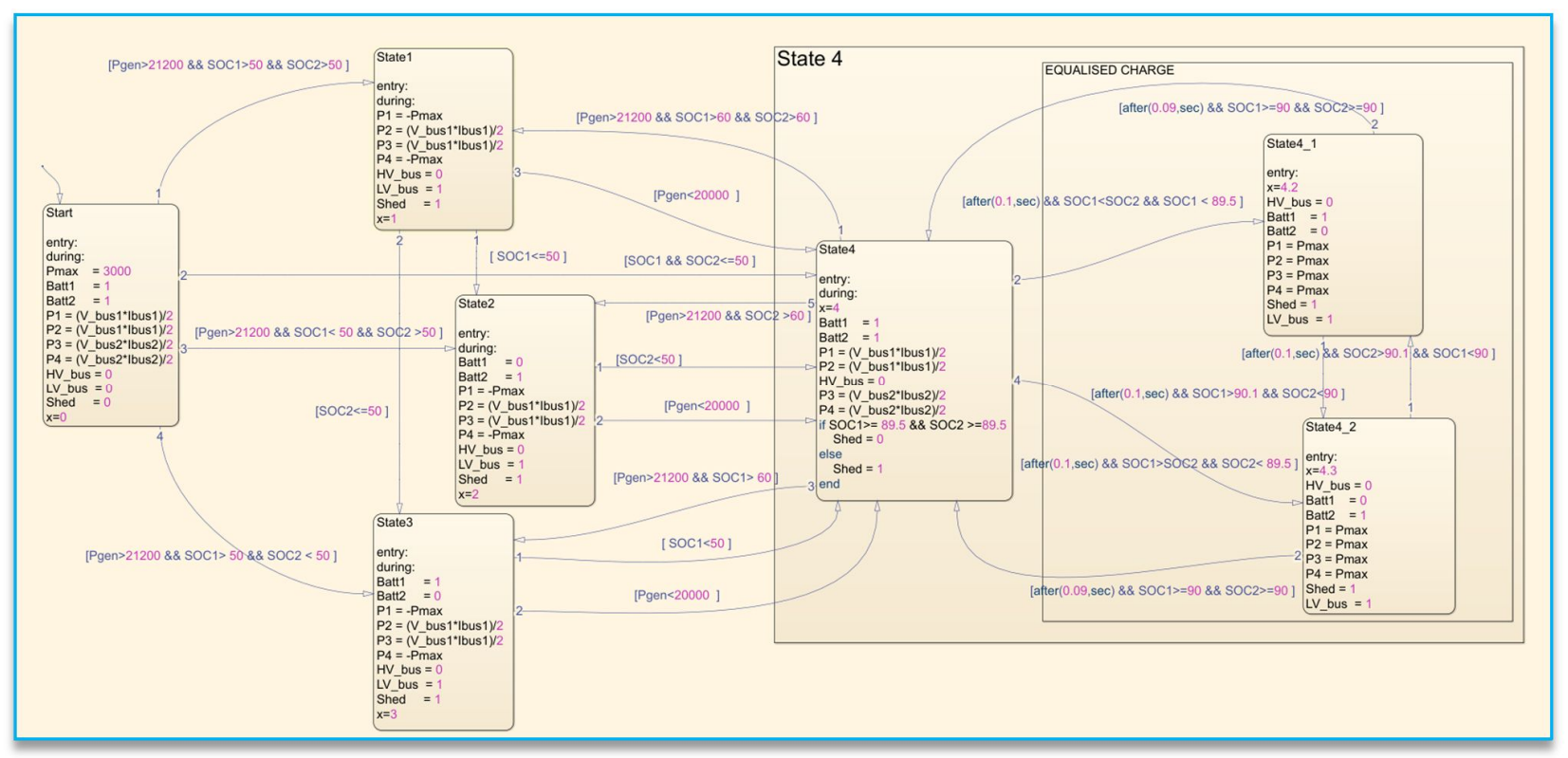

Fig. 3. Model of the finite state machine for the case under study in Simulink environment

Every state of the system under study represents a different configuration of the EPS. In order to build the finite state machine for the case study, a number of parameters are used as shown in the state blocks and over the transition arrows in Fig. 3. $P_{\max }$ represents the maximum power in watt. Batt 1 and Batt 2 represent the status of the contactors that are used to connect or disconnect the batteries 1 and 2 respectively. For instance when Batt $_{1}=1$, the contactor is closed and battery 1 is connected. $P_{1}, P_{2}$, $P_{3}$ and $P_{4}$ are the power that the power electronic converters $1,2,3$ and 4 have to convert respectively and are calculated based on the voltage of the LV bus $V_{B u s}$ and the current through the LV bus $I_{B u s}$. The contactors used to connect the two HV buses and the two LV buses are called $H V_{B u s}$ and $L V_{B u s}$ respectively. The variable Shed is used to shed the power of the low priority low voltage load, while the variable $x$ represent the state in which the system is operating. When the de-icing system needs to operate, the power request for the HV loads will increase. Hence depending on the operation modes of the system, whether in normal condition or de-icing condition, and the state of charge of the two batteries, the controller will reconfigure the system based on the logics in the state transition table II. The results of a few simulation cases are discussed in the next subsection.

\section{E. Simulation results}

In this case study, the system is initially operating in normal conditions (operating mode 1 as defined in Table I). Assuming intense ice formation, which is the worse-case scenario for the EPS, (operation mode 2 as defined in Table I), the EPS has to supply the de-icing system with an additional $(2 \times 6 \mathrm{~kW})$ power for a duration of 6 minutes as considered in this case study [20]. Fig. 4 shows the power request for the de-icing system from the HV load 1 rising from $15 \mathrm{~kW}$ to $21 \mathrm{~kW}$ at time $12 \mathrm{~s}$, which is similar for $\mathrm{HV}$ load 2. At time $12 \mathrm{~s}, \mathrm{SOC} 1$ is $70 \%$ and SOC 2 is $85 \%$, as shown in Fig. 5; hence the system is in state 1 at time $12 \mathrm{~s}$ as shown in Fig. 10.

The power system remains in state 1 from time $12 \mathrm{~s}$ to 286.9 s. At time 286.9 s, when SOC1 drops to $50 \%$ with SOC2 being still above $50 \%$, the controller changes the system configuration from state 1 to state 2 , in accordance with Table II. The system is in state 2 until time $t=372$ s, as shown in Fig. 10.

At time 372 s, i.e. 6 mins after activation of operation mode 2 , the de-icing operation terminates and the system is moved to state 4 as per Table II, and as depicted in Fig. 5. In system state 4 , the battery 1 is charged first until its SOC reaches $90 \%$ at time $1438 \mathrm{~s}$, as represented by sub-state 4.1 in Fig. 3. Thereafter, battery 2 starts charging from time $1438 \mathrm{~s}$ to time $2452 \mathrm{~s}$, as represented by sub-state 4.2 in Fig. 3 . It is to be noted that when the system is in state 1 and 2 from time 12 s to 372 s, PEC 1 and 4 are in boost mode, each transferring $3 \mathrm{~kW}$ of power from the LV bus to the HV bus, as shown in Fig. 7.

Fig. 5 shows the characteristic of one of the generators. The spike in Fig. 5 at time 12s is due to the controller action which reverses the power flow of one power electronic converter. Of note is that the power required from the generator immediately falls back to $21 \mathrm{~kW}$ after the spike, which shows that the generator does not go in overload.

The controller has also activated load shedding from time $12 \mathrm{~s}$ to $2452 \mathrm{~s}$, to first supplement power for the deicing system in states 1 and 2 and then to recharge the batteries in state 4 , as can be seen from Fig. 8. In addition, the PECs 5 and 6 have ensured that the voltage of the LV buses is maintained at $28 \mathrm{~V}$ during the state transitions as can be seen in Fig. 9. 


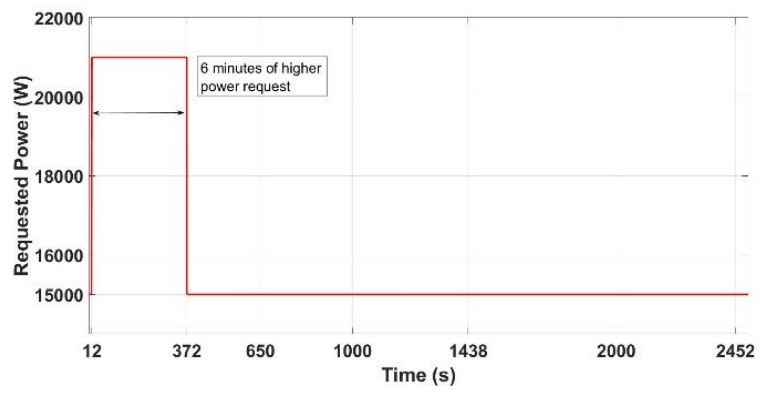

Fig. 4. Request of total of $12 \mathrm{~kW}$ power for de-icing system with (i) 6 $\mathrm{kW}$ to HV load 1 and (ii) $6 \mathrm{~kW}$ to HV load 2, respectively

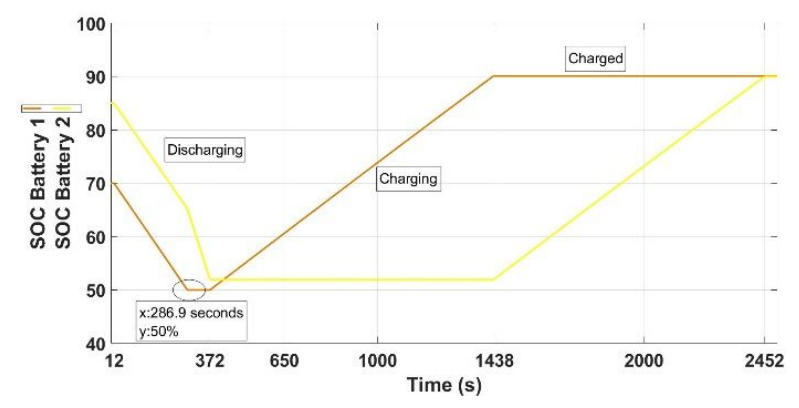

Fig. 5. State of charge of batteries 1 and 2 as the system changes states

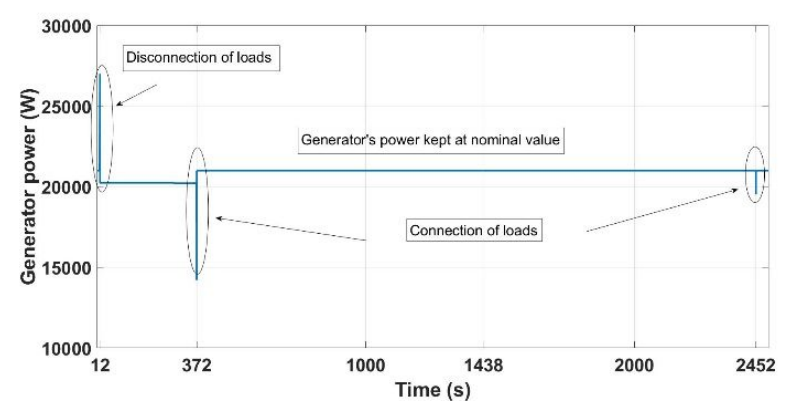

Fig. 6. Power characteristic of one generator, which shows that the generator does not go into overload.

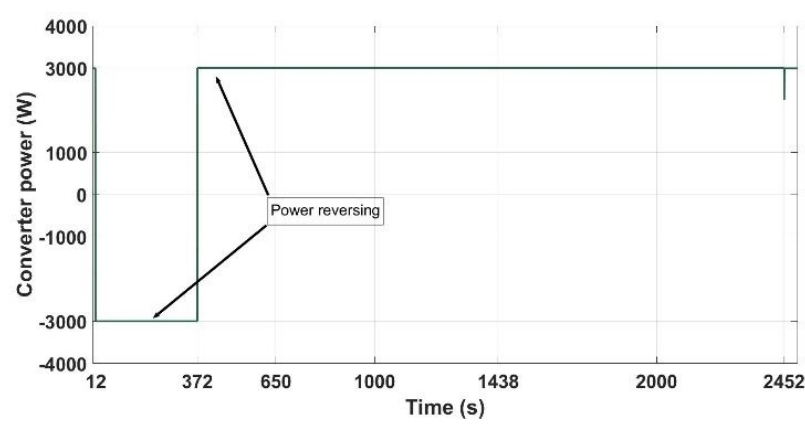

Fig. 7. Power characteristic of power electronic converter 1 which shows power flow reversal at $\mathrm{t}=372 \mathrm{~s}$.

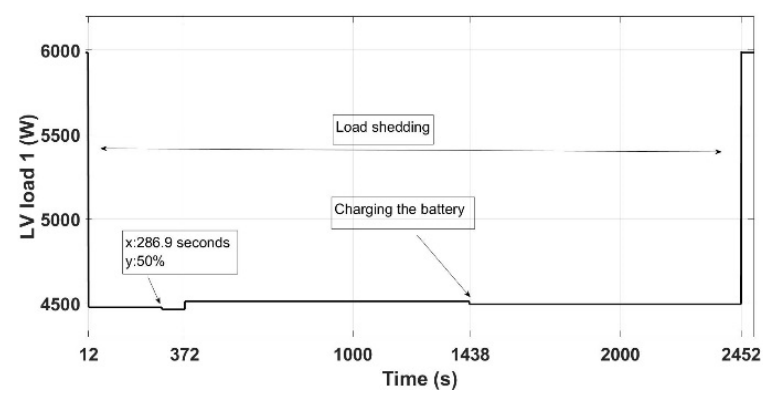

Fig. 8. Power characteristic of the LV bus1. At time $\mathrm{t}=12 \mathrm{~s}$ to $2452 \mathrm{~s}$ power drops from $6 \mathrm{~kW}$ to $4.5 \mathrm{~kW}$ due to load shedding to supply de-icing systems in states 1 , and 2 and then to charge batteries in state 4 .

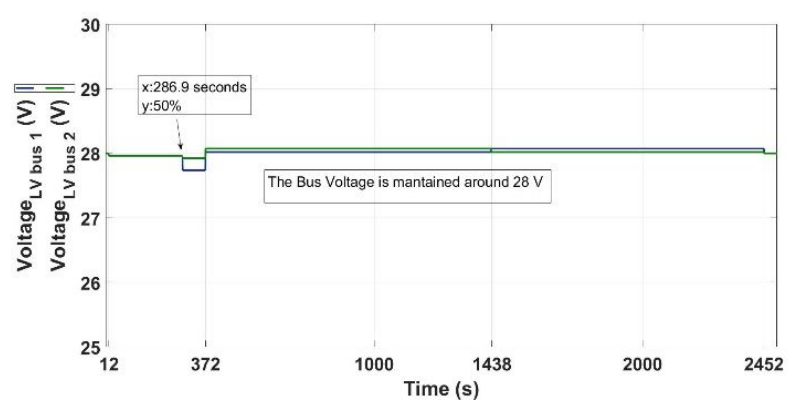

Fig. 9. Voltage on low voltage buses 1 and 2 maintained at $28 \mathrm{~V}$

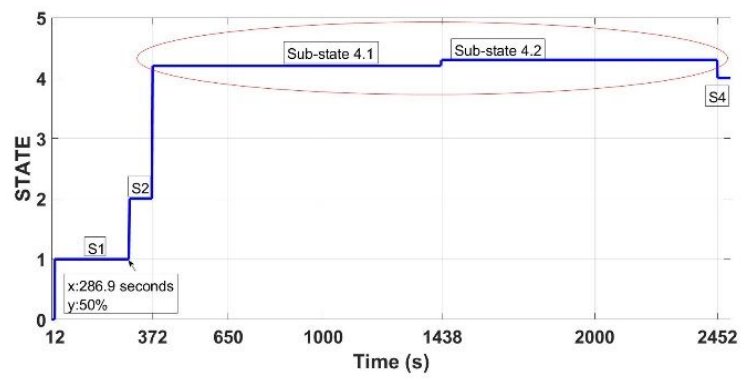

Fig. 10. System states for the case study. System is in (i) state 1 from $t=12 \mathrm{~s}$ to $\mathrm{t}=287 \mathrm{~s}$ (ii) state 2 from $\mathrm{t}=286.9 \mathrm{~s}$ to $\mathrm{t}=372 \mathrm{~s}$ (iii) state 4 from $\mathrm{t}=1438 \mathrm{~s}$

\section{CONCLUSION}

This paper has demonstrated the benefits of incorporating a smart controller in the design of the electrical network of future aircrafts. The electrical power systems of modern aircraft are more flexible and easily reconfigurable mainly due to the use of power electronic converters. This paper has exploited the reconfigurability feature of a representative MEA EPS and has devised a smart control strategy aimed at reducing the overload on its two generators. Through simulations it has been showed how an overload of $28.6 \%$ can be avoided on the generator by application of a smart controller. This implies that smaller onboard generators can be used for the electrical network with consequent reduction of aircraft weight and fuel consumption.

\section{ACKNOWLEDGMENT}

This work is funded by the INNOVATIVE doctoral programme. The INNOVATIVE programme is partially funded by the Marie Curie Initial Training Networks (ITN) action 
(project number 665468) and partially by the Institute for Aerospace Technology (IAT) at the University of Nottingham.

\section{REFERENCES}

[1] B. Sarlioglu and C. T. Morris, "More Electric Aircraft: Review, Challenges, and Opportunities for Commercial Transport Aircraft," IEEE Transactions on Transportation Electrification, vol. 1, pp. 54-64, 2015.

[2] V. Madonna, P. Giangrande, and M. Galea, "Electrical Power Generation in Aircraft: review, challenges and opportunities," IEEE Transactions on Transportation Electrification, pp. 1-1, 2018.

[3] P. Wheeler and S. Bozhko, "The More Electric Aircraft: Technology and challenges," IEEE Electrification Magazine, vol. 2, pp. 6-12, 2014.

[4] A. Al-Timimy, P. Giangrande, M. Degano, M. Galea, and C. Gerada, "Comparative study of permanent magnet-synchronous and permanent magnet-flux switching machines for high torque to inertia applications," in 2017 IEEE Workshop on Electrical Machines Design, Control and Diagnosis (WEMDCD), 2017, pp. 45-51.

[5] P. Giangrande, C. I. Hill, S. V. Bozhko, and C. Gerada, "A novel multi-level electro-mechanical actuator virtual testing and analysis tool," in 7th IET International Conference on Power Electronics, Machines and Drives (PEMD 2014), 2014, pp. 1-6.

[6] S. A. Odhano, P. Giangrande, R. I. Bojoi, and C. Gerada, "Self-Commissioning of Interior PermanentMagnet Synchronous Motor Drives With HighFrequency Current Injection," IEEE Transactions on Industry Applications, vol. 50, pp. 3295-3303, 2014.

[7] D. Izquierdo, R. Azcona, F. J. L. d. Cerro, C. Fernández, and B. Delicado, "Electrical power distribution system (HV270DC), for application in more electric aircraft," in 2010 Twenty-Fifth Annual IEEE Applied Power Electronics Conference and Exposition (APEC), 2010, pp. 1300-1305.

[8] İ. Kocaarslan and E. Çam, "Fuzzy logic controller in interconnected electrical power systems for loadfrequency control," International Journal of Electrical Power \& Energy Systems, vol. 27, pp. 542-549, 2005/10/01/2005.

[9] I. H. Altas and A. M. Sharaf, "A novel maximum power fuzzy logic controller for photovoltaic solar energy systems," Renewable Energy, vol. 33, pp. 388399, 2008/03/01/ 2008.

[10] B. Tang, S. Yang, L. Wang, and H. Zhang, "Power priority algorithm in application to aircraft distribution network reconfiguration," in 2016 International Conference on Electrical Systems for Aircraft, Railway, Ship Propulsion and Road Vehicles \& International Transportation Electrification Conference (ESARS-ITEC), 2016, pp. 1-5.
[11] A. Pnueli, "The temporal logic of programs," presented at the Proceedings of the 18th Annual Symposium on Foundations of Computer Science, 1977.

[12] A. Pnueli and R. Rosner, "On the synthesis of a reactive module," presented at the Proceedings of the 16th ACM SIGPLAN-SIGACT symposium on Principles of programming languages, Austin, Texas, USA, 1989.

[13] L. Xuesen, "Multi-behaviors Finite State Machine," in 2009 IEEE Youth Conference on Information, Computing and Telecommunication, 2009, pp. 201203.

[14] D. Pederson. (25/05/2018). Finite State Machines : https://ptolemy.berkeley.edu/projects/embedded/rese arch/hsc/class/ee249/lectures/l4-FSM-CFSM.pdf.

[15] V. Madonna, P. Giangrande, C. Gerada, and M. Galea. (2018, Thermal analysis of fault tolerant electrical machines for MEA applications. The Journal of Engineering. Available: $\quad \underline{\text { htp://digital- }}$ library.theiet.org/content/journals/10.1049/joe.2018.0 $\underline{040}$

[16] X. Giraud, H. Piquet, M. Budinger, X. Roboam, M. Sartor, and S. Vial, "Knowledge-based system for aircraft electrical power system reconfiguration," in Electrical Systems for Aircraft, Railway and Ship Propulsion (ESARS), 2012, 2012, pp. 1-6.

[17] X. Giraud, M. Sartor, X. Roboam, B. Sareni, H. Piquet, M. Budinger, et al., "Load allocation problem for optimal design of aircraft electrical power system," International Journal of Applied Electromagnetics and Mechanics, vol. 43, pp. 37-49, 2013.

[18] N. Piterman, A. Pnueli, and Y. Sa'ar, "Synthesis of reactive(1) designs," presented at the Proceedings of the 7th international conference on Verification, Model Checking, and Abstract Interpretation, Charleston, SC, 2006.

[19] H. Xu, "Design, Specification, and Synthesis of Aircraft Electric Power Systems Control Logic," ed, 2013.

[20] "The more electric aircraft: Why aerospace needs power electronics?," in 2009 13th European Conference on Power Electronics and Applications, 2009, pp. 1-30.

[21] R. K. Jeck, "Icing Design Envelopes (14 CFR Parts 25 and 29, Appendix C) Converted to a Distance-Based Format," U.S. Department of Transportation Federal Aviation Administration, p. 55, 2002.

[22] C. Spagnolo, S. Sumsurooah, C. I. Hill, and S. Bozhko. (2018, FINITE STATE MACHINE CONTROL FOR AIRCRAFT ELECTRICAL DISTRIBUTION SYSTEM. The Journal of Engineering. Available: $\underline{\mathrm{http}: / / \text { digital- }}$ library.theiet.org/content/journals/10.1049/joe.2018.0 $\underline{039}$ 